\title{
Comparative Study Of Preschool Children's Current Health Issues And Health Education In New Zealand And Japan
}

\author{
Kanae Watanabe, Kanagawa University, Japan
}

Annette Dickinson, Auckland University of Technology, New Zealand

\begin{abstract}
In New Zealand and Japan, despite health education on food, exercise, and hygiene, children's health is an important concern in preschools. This study investigated the relationship between children's health and health education in New Zealand and Japan using a qualitative interpretative descriptive design method and semistructured interviews with preschool teachers. Major children's health issues identified by preschool teachers in New Zealand were asthma, allergies, and dental hygiene. Although few preschool children are overweight in New Zealand, it becomes a serious concern in primary school. Identified as a suspected cause of children's health problems was parents providing their children with sweet and/or unhealthy foods. Preschool teachers want parents to understand and implement health education, and they stated that parents' education was necessary. In Japan, children's health problems identified by teachers were allergies, food preferences, and sleep deprivation. The suspected causes included too much convenience, parents' irregular lifestyles because they were busy, and parents' depending on preschools to discipline children in ways that should be done at home. The goals for preschool health education were similar in New Zealand and Japan. The goals should be to obtain lifelong health knowledge, an ability to make wise health-related decisions in adulthood, and healthy lifestyle choices for themselves and their families. Some children's health issues were beyond the scope of the abilities of individual preschools. Therefore, the entire nation and government should work together to cope with children's health issues and health education.
\end{abstract}

Keywords: Preschool; Health Education; New Zealand; Japan

\section{INTRODUCTION}

C n New Zealand (Ministry of Education, New Zealand, 2016) and Japan (Ministry of Education, Culture, Sports, Science and Technology, Japan, 2008), health is one of the most important education subjects in early childhood education curricula. This differs from primary and secondary schools, where language, science, and mathematics are important, while health education is treated as a minor subject in preschools. However, despite the significant attention paid to health education in preschools, children's health remains an important and serious issue in both countries. In New Zealand, a comparison of survey data of 2011-2012 to that of 2006-2007 on children aged 2 to 14 years indicated that obesity was becoming more common, asthma remained a common health condition, and diagnosed emotional and behavioral problems increased (Ministry of Health, New Zealand, 2012). In Japan, children tend to have night-oriented lifestyles, video- and television-viewing time has increased while outdoor activities have decreased, and the establishment of basic health and life skills such as brushing teeth and self-toileting is delayed (Etoh, 2011: Central Education Council 24th, 2002). Health and healthy lifestyles throughout the life course start in infancy, and children's health is the foundation of future health and healthy aging (Science Council of Japan, 2010). The goal of this study was to examine children's health conditions and health education issues in New Zealand and Japan to improve and develop preschool children's health. 


\section{METHODS}

A qualitative interpretive descriptive design was employed through semi-structured interviews with seven teachers at seven preschools each in New Zealand and Japan (Table 1). The New Zealand preschool teachers were interviewed in English and the Japanese teachers in Japanese by one author (KW). All interviews were audiotaped and transcribed. Data was analyzed using Braun and Clarke's framework for thematic analysis (Braun \& Clarke, 2006).

Table 1. Interview participants at the two study sites

\begin{tabular}{l|l|l}
\hline \multicolumn{1}{c}{ Characteristic } & \multicolumn{1}{|c}{ New Zealand } \\
\hline Preschool & $\begin{array}{l}\text { Two kindergartens and five education and care } \\
\text { centers (total seven preschools) }\end{array}$ & $\begin{array}{l}\text { Two kindergartens and five nursery schools (total } \\
\text { seven preschools) }\end{array}$ \\
\hline Area & Auckland & Tokyo, Chiba (adjacent to Tokyo) \\
\hline Teachers & Seven females & Seven females \\
\hline
\end{tabular}

New Zealand and Japan employ plural teacher-led early childhood education services. In New Zealand, the major ones are kindergartens (children aged 3-5 years) and education and care centers (children aged 0-5 years). Japan has kindergartens (children aged 3-5 years) and nursery schools (children aged $0-5$ years). The curricula in these schools are similar in New Zealand and Japan. This study refers to them all as "preschools."

The following eight questions guided the semi-structured interviews:

1. What are the health concerns of the teachers at your preschool?

2. What do you think are the main causes of these health issues?

3. What do you do at your preschool regarding health education?

4. Is this education guided by Te Whariki (New Zealand) / Course of study for kindergarten (Japan): [governmental curriculum]?

5. In your opinion, is the government curriculum adequate for improving the health of the children at your preschool?

6. What support do you need to conduct health education at your preschool?

7. In your opinion, what are the outcomes of the health education received by the children at your preschool?

8. In what ways could health education be developed or changed?

The Auckland University of Technology Ethics Committee (AUTEC 13/166) approved the New Zealand phase of this study. The Japanese phase of the study complied with the guidelines of the Japanese Society of Physical Education Health and Sports Science, Ethics of Researchers, 2011.

\section{RESULTS}

\section{Children's Health Issues Identified by Preschool Teachers}

Table 2. Children's health issues identified by preschool teachers in New Zealand and Japan

\begin{tabular}{|c|c|c|}
\hline Health Issue Rank & New Zealand & Japan \\
\hline 1 (most common) & Asthma & Allergy \\
\hline 2 (second-most common) & Allergy & Food preferences \\
\hline 3 (third-most common) & Dental hygiene & Sleep deprivation \\
\hline After preschool & Obesity & \\
\hline
\end{tabular}




\section{New Zealand}

One of the children's health issues most often mentioned by preschool teachers was asthma. New Zealand had a high prevalence of asthma, with 1 in 7 children aged 2-14 years (15\%) diagnosed with the problem (New Zealand Health Survey, 2015). Some causes of asthma were damp and dusty housing conditions. However, even children living in clean and organized houses suffered from asthma, indicating that not all the causes had been identified. Other frequently mentioned health issues were allergies and dental health. According to the teachers, parents' provision of unhealthy, inexpensive food (sweets, soft drinks, and foods low in nutritional value) caused these two problems. As background, the underlying causes were identified as parents' lack of education and financial stress. In New Zealand, many healthy foods such as fresh vegetables and fruits were relatively expensive compared to less healthy options such as instant or convenience foods. In New Zealand, economic disparity was a serious social issue that led to education and health disparities among children (St. John \& Wynd, 2008).

Japan

Three major children's health issues identified by preschool teachers were allergies, food preferences, and sleep deprivation. Teachers pointed out that parents' lifestyles and environmental changes (natural and social) experienced by children influenced their health. Teachers guessed that Japanese parents were too busy to return home from work before evening or to get adequate sleep.

\section{Health Education Delivered by Preschool Teachers}

All preschool teachers in this study in New Zealand and Japan emphasized that nutrition, physical activity, and hygiene such as washing hands, brushing teeth, and wearing clean clothing comprised health education. Teachers conducted health education programs, prepared study materials, and taught children simple and practical steps toward health. Apparently, the children enjoyed health education, which was learned through play, and understood the meaning of healthy eating, the importance of physical activity, and so on. If health education continued in primary schools, health problems such as obesity might be controlled. However, the preschool teachers told us that as primary school teachers had more students than preschool teachers, it would be difficult for them to carefully monitor the health behaviors of all students. In addition, the preschool teachers guessed that in primary school many academic subjects such as math and language took up much of the day, so it would be difficult to find sufficient time for health education.

\section{Outcomes of Health Education}

New Zealand

According to the teachers, the children understood which foods were healthy and why they should exercise, and became independent and could make their own decisions. Moreover, in the future, these children should be able to make wise healthcare decisions, obtain lifelong knowledge on health, and realize healthy lifestyles.

Japan

According to the teachers, these children took good care of their bodies. In addition, the children helped and encouraged their friends to be healthy. The children understood that they would need to be responsible for their health and work to solve health problems on their own. Of course, the children gained physical strength. The teachers stated that health education in preschool should support lifelong knowledge about health and healthy lifestyles in the future.

\section{Requirements for Health Education in Preschools}

In New Zealand and Japan, the teachers reported that the most important requirement for conducting health education was parents' support. Logically, health education should be conducted both at home and at school, because health education limited to preschool would not be effective. However, the present situation is not so. The 
teachers in New Zealand commented on the need to educate parents, because uneducated parents did not know the importance of health education or how to live healthy lives. The teachers in Japan commented that parents had recently become dependent on preschools to discipline and educate their children in ways that should be done at home.

Furthermore, the teachers in New Zealand reported that they needed government involvement in preschools to observe the situation. They explained that the government was promoting privatization of early childhood education, which had caused a workforce shortage because of salary cuts and lack of professional training for teacher development. Furthermore, they stated that they needed Plunket (provider of support services for children aged under five years in New Zealand) or public health professionals' support and advice, because universities did not offer health education courses. The teachers in Japan said that they also needed the understanding of residents. In Japan, the lack of nursery schools was a serious problem, but new nursery schools could not open, because residents in the area resisted them, citing the children's noisy presence. Children at existing nursery schools could not play outside, because local residents complained about the noise.

\section{Development and/or Changes to Health Education in Preschools}

\section{New Zealand}

The teachers stated that the healthy foundation developed during preschool should continue in primary school. All teachers commented and were anxious about children's obesity after they graduated from preschool. Obesity was prevented at the preschool ages, but in primary schools, children suddenly became bigger and the ratio of obese children was increasing. The health curriculum should change to help children prevent obesity. Currently, the early childhood education curriculum is conceptual and universal, but will become more detailed. Furthermore, health education for parents should be developed and healthy foods should be affordable to realize children's health and effective health education.

\section{Japan}

In the future, children's health and health education should be managed by the nation overall, because natural and social environmental maintenance is needed, which is beyond the scope of the abilities of individual preschools. Some teachers commented that education on abuse and sex crimes should be taught in preschools, because unfortunately, victims were becoming younger. In New Zealand, education on safety to protect children from abuse was in place for children of all ages. However, Japan did not teach children about abuse and sex crimes through the formal curricula. Radioactive pollution is also a serious health issue and including it in the health curriculum for children should be important, because the problem is persistent.

\section{CONCLUSION}

Although it was found that children's health issues were not identical in New Zealand and Japan, health education was a major subject in preschools, and nutrition, physical activity, and hygiene were the main topics. New Zealand and Japanese preschool teachers stated that lifelong knowledge about health and healthy lifestyles in the future were the goals of health education in preschools. However, teachers in New Zealand perceived these as inevitable outcomes of health education, whereas teachers in Japan considered them as goals. Paradoxically, in New Zealand, one children's health issue - obesity - became serious shortly after leaving preschool and entering primary school. Children's environments are changing; therefore, health education should change to keep up with children's current health issues. Importantly, some children's health issues were beyond the abilities of individual preschools, and the government should observe and know the reality of the situation. The entire nation or government should work together to cope with children's health issues and health education.

\section{ACKNOWLEDGEMENTS}

This study was supported by the Japan Society for Promotion Science (JSPS) Grant-in-Aid for Scientific Research (C), Grant Number 24600025. Dr. Tineke Water, Dr. Andrew Gibbons, and Ms. Desma Cornhill of Auckland 
University of Technology helped us to conduct the interviews and provided important information about New Zealand's early childhood educational system and curricula.

\section{AUTHOR BIOGRAPHIES}

Dr. Kanae Watanabe has taught and researched health and physical education at universities. Her doctoral research (PhD 1994) focused on motor control, specifically the influences of neck movement and position on limb muscle activities. Her current research interests mainly focus on children's health and physical education and in lifetime health. In 2012 through 2013, she refereed a governmental research grant. In 2013, she went to New Zealand on sabbatical and researched the children's health and health education concerns of New Zealand and Japan.

Dr. Annette Dickinson has held numerous leadership positions at Starship Children's Hospital as Nurse Consultant and Advisor. The focus of her doctoral research (PhD 2004) was a Heidegerrian Phenomenological Study that explored the relationship between families and healthcare practitioners. Her research and clinical interests relate to chronic illness and disability in childhood, children's health literacy and illness experiences, healthcare service delivery to children and families, and the development of a professional workforce for children's healthcare services.

\section{REFERENCES}

Braun, V., \& Clarke, V. (2006). Using thematic analysis in psychology. Qualitative Research in Psychology, 3(2) 77-101.

Central Education Council, 24th. (2002). Ministry of Education, Culture, Sports, Science and Technology, Japan. Retrieved from http://www.mext.go.jp/b_menu/shingi/chukyo/chukyo0/gijiroku/attach/1344534.htm

Etoh, T. (2011). The Japanese Society of Child Health: Comparative continued study of infants' health. Kitakyushu: Yoshimikosan Co. Ltd, 1-17 (in Japanese).

Ministry of Education, Culture, Sports, Science and Technology, Japan. (2008). Course of study for kindergarten (English version). Retrieved from http://www.mext.go.jp/a_menu/shotou/newcs/youryou/eiyaku/_icsFiles/afieldfile/2011/01/13/1298368_1.pdf

Ministry of Health, New Zealand. (2012). The health of New Zealand children 2011/12 (25-39). Wellington: Ministry of Health, New Zealand.

Ministry of Education, New Zealand. (2016). Te Whariki. Retrieved from https://education.govt.nz/assets/Uploads/Te-WharikiEarly-Childhood-Curriculum-04-11-low-res.pdf

New Zealand Health Survey. (2015). Annual update of key findings 2014-2015. Retrieved from https://www.health.govt.nz/publication/annual-update-key-results-2014-15-new-zealand-health-survey

Science Council of Japan. (2010). Health promotion for Japanese children (in Japanese). Retrieved from http://www.scj.go.jp/ja/info/kohyo/pdf/kohyo-21-h99-1.pdf

St. John, S., \& Wynd, D. (2008). Left behind: How social \& income inequalities damage New Zealand children, 12-26. Auckland: Child Poverty Action Group Inc. 
NOTES 